\title{
Benefit Evaluation Approach of Consumer Side Energy Management Systems Focusing on Enterprise Productivity
}

\author{
Ken Kuroda, Hideki Magori, Tomiyasu Ichimura, and Ryuichi Yokoyama
}

\begin{abstract}
Energy management systems (EMSs) for electricity consumers which manage energy consumption and control some energy consuming equipment in consumer side are expected to be one of effective measures for optimized energy supply and utilization. On the other hand, it is difficult to clarify the benefit of EMS installation, because EMS does not reduce energy consumption only with its installation but improvement or optimization of energy usage in consumer side should be necessary. In addition, whereas advantages of EMS installation such as energy cost and $\mathrm{CO} 2$ emission reduction have been considered, negative (trade-off) factors of energy saving have not been discussed enough. This paper proposes a benefit evaluation approach of EMS and the EMS installation impact on enterprise productivity is considered. Also, simulations using Monte Carlo method are conducted and their results are discussed and evaluated.
\end{abstract}

Index Terms-Demand control, energy management system, Monte Carlo method, work productivity.

\section{INTRODUCTION}

For the smart grid realization, collaborative control between power supply and demand is expected and it should be necessary to control electrical demand corresponding to requirements from power supply side. Energy management system (EMS) for electricity consumers is one of expected measures to contribute to the collaborative control, and Building Energy Management System (BEMS), Factory Energy Management system (FEMS) and Home Energy Management System (HEMS) are well known EMS examples in demand side. By the utilization of such EMSs, it is expected that consumers can reduce both their electricity peak load and total consumption by effective and efficient electricity utilization, and also power suppliers can realize effective and efficient power supply with demand peak cut and shift by the utilization of such controllable electrical demand.

Whereas EMS installation provides such various benefits to both consumer and suppliers, potential EMS consumers should have to make a difficult decision if they would install EMS for their effective energy utilization. EMS requires installations of hardware such as metering devices and ICT related hardware and software before the beginning of the service. Although such initial and additional operation cost should be recovered by the benefit from energy cost reduction by the effect from EMS basically, it is difficult for consumers

Manuscript received April 5, 2014; revised June 30, 2014.

Ken Kuroda, Hideki Magori, and Ryuichi Yokoyam are with Waseda University, 4-1, Okubo 3-chome, Shinjuku-ku, Tokyo, 169-8555, Japan (e-mail: kuroken@fuji.waseda.jp).

Tomiyasu Ichimura is with Fujitsu Limited, 17-25, Shinkamata 1-chome, Ota-ku, Tokyo, 144-8588, Japan (e-mail: ichimura@jp.fujitsu.com). to evaluate the benefit from EMS at the pre-installation of EMS. In addition, it is necessary to monitor the influence of energy saving to consumers' business productivity so as not to decrease consumers' profitability. It means that energy saving by EMS should be executed with maintaining consumers' current business productivity at least. Therefore, it is necessary to clarify and quantify the effect of EMS installation before the actual EMS related investment, and the initial cost recovery period should be as short as possible in order to promote EMS as one of future demand control measures.

\section{CONSUMER Side ENERGy MANAGEMENT Systems AND THEIR STUDIES}

In order to realize effective energy consumption, various kinds of EMSs are proposed. In this section, consumer side EMS, which is focused in this paper, is defined and purposes of this EMS are considered. In addition, studies for providing effective energy management are discussed.

\section{A. Categorization of EMS}

In general, EMS is defined as the information system which supports optimization of energy consumption in buildings, factories and households etc., utilizing information communication technology (ICT). On the other hand, regional and wide-area energy supply and demand balancing system is also called EMS, and recently some are called community EMS (CEMS). These EMSs have been considered to be applied for various purposes such as energy saving, $\mathrm{CO} 2$ emission reduction and disaster resilient energy infrastructure. Because there are various types of EMS, this paper defines major EMS types for the purpose of clarifying the characteristics of them.

Firstly, EMSs can be categorized by supply side EMS and demand side EMS. Supply side EMSs are for the stable power supply and are managed by utility companies and regional system operators. Demand side EMS is for the consumers' benefit increase such as energy cost reduction et al., and BEMS, FEMS and HEMS are categorized in the type.

Referring to energy consumption status data in Japan [1], 2009 energy consumption in the consumer category, which is composed of commercial and household use, increased 1.38 and 1.23 times respectively compared with 1990, while energy consumptions in transportation and industry categories were 1.06 and 0.88 times respectively. Therefore, energy reduction in consumer area is one of big challenges in Japanese energy policy and effective EMS application is one of expected measures. Fig. 1 shows EMS categorization defined in this paper, and this paper focuses on the consumer 
side EMS and especially focused on EMS for commercial sector, because clarification of EMS installation benefit in the area should be the most effective to promote EMS and optimize energy consumption.

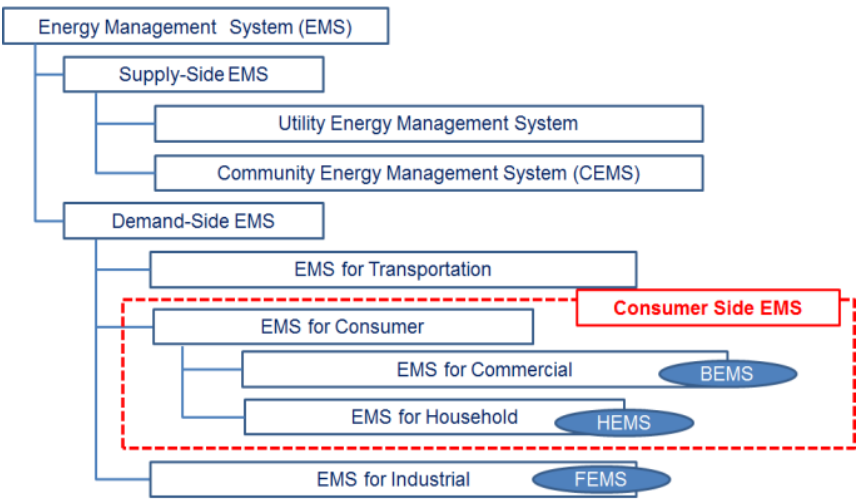

Fig. 1. Categorization of energy management systems in this paper.

\section{B. Functions and System Structure of Consumer Side EMS}

In general, EMS collects energy-related data and makes visualization using these data firstly, then energy consumption status is analyzed and optimization would be conducted. In addition, sometimes demand monitoring and controls of energy consumption devices are also conducted as necessary. In order to realize these functions, EMS requires many components such as energy data measuring devices, data transfer network and information systems which totalize collected data and analyze these data. In addition, optimized operation schedules and their transformation to control devices should be required in order to realize optimal operation using analyses data. Fig. 2 shows an overview of general required system structure in EMS.

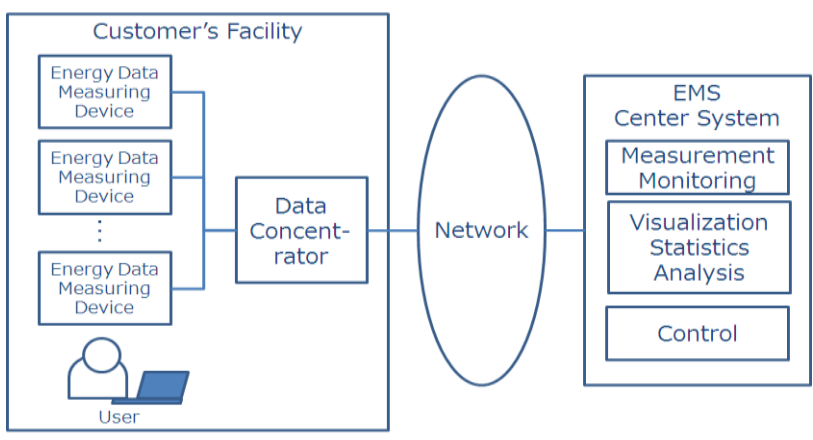

Fig. 2. Overview of EMS structure.

\section{Studies of Energy Saving and its Relation with Work Productivity}

EMS related studies have been executed and building energy management is one of especially active research areas recently. A building energy management solution using ZigBee and power line communication is proposed in [2] and it describes that the proposed solution is able to save $34 \%$ of total energy consumption for the building. In [3], multiple gateway system for wireless sensor network is proposed focusing on huge data transferring and processing, and an efficient data transmission method which decreases power consumption and data delay for sensor data collection is provided. In [4], an energy management methodology using multi-agent systems for BEMS with combined heat and power system optimization is described and a case study is presented for a typical food center to demonstrate the proposed method. As an actual demonstration project case study, [5] describes a BEMS solution including energy usage, cost and carbon emissions reduction and installed on smart grid test bed in Jeju Island, South Korea. In this way, many researches related to advanced technologies such as renewable energy sources (RES) and energy saving aspects has been conducted, however studies for the impact of energy reduction by EMS have not been discussed sufficiently.

On the other hand, some statistic researches have been conducted with regard to relation between work environment and work productivity or performance. The literature relating work performance with temperature is analyzed in [6], and it found a general decrement in work performance. Also [7] explains the importance and needs of the concept of productivity in building environment, and a conceptual diagram is proposed for the evaluation of the effect of indoor environmental quality on productivity.

\section{Benefit Quantification Focused on Productivity Change by the EMS Installation}

Based on the aspect of consumer benefit, quantification of EMS installation effect considering enterprises' productivity or profit should be critical in order to realize optimal energy utilization. Therefore, an effective impact evaluation method should be achieved by the collaboration of EMS related energy management functions and statistical analysis related to work performance with energy environment.

\section{APPROACH FOR BENEFIT QUANTIFICATION OF ENERGY MANAGEMENT SYSTEM INSTALLATION}

In this section, purposes and challenges of consumer side EMS are discussed and procedures for the establishment for quantification of EMS installation benefit are considered.

\section{A. Benefit Realization Concept of Consumer Side EMS}

Major objectives for consumer side EMS should be an optimization of energy consumption and cost reduction. Energy cost reduction should be realized by following 3 elements mainly.

\section{1) Basic charge reduction by peak cut}

Generally, electricity price consists of basic charge and metered charge. By the reduction of peak time electricity usage by EMS, basic charge, which is decided by the peak time electricity usage, can be reduced and then total electricity price should be reduced.

\section{2) Total electricity consumption reduction by the} elimination of wasted energy consumption

There must be wasteful electricity usage which is not necessary to consume such as standby electricity and is clarified by energy consumption visualization. By the reduction of such wasteful electricity consumption, total electricity consumption should be reduced.

\section{B. Energy Cost Optimization by Peak Shift}

This type of cost reduction is achieved by electricity price programs such as Time of Use (TOU) etc., in which electricity unit price in each time slot is different. By the control of 
electricity consumption behavior corresponding to electricity price for each time slot, optimal electricity consumption will be addressed. Demand response (DR) is a service in which incentives from utility companies and system operators, who would get benefit by demand reduction by consumers, should be provided to the consumers and it is included in this category. Fig. 3 shows an overview of benefit realization concept of consumer side EMS.

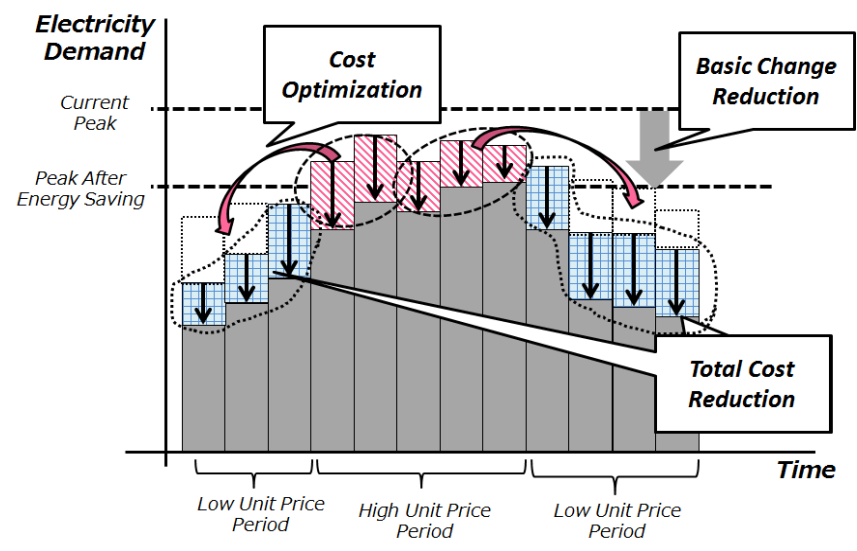

Fig. 3. Benefit realization concept of consumer side EMS.

\section{Challenges for the Expansion of Consumer Side EMS}

If consumer side EMS installation benefit would be clarified in commercial sector, this should be important for business administration in enterprises and many of them should be proactive for the installation of EMS. In Japan, EMS has been expected as the one of solutions for the effective energy utilization and for the energy shortage due to the Great East Japan disaster. However, the number of EMS installation in consumer sector has not become large as most EMS providers expected, so far.

According to "2010 White Paper on Small and Medium Enterprises in Japan" [8], energy efficiency in small and medium enterprises (SMEs) have not been improved compared with major enterprises, and "Energy Conservation through Investment" such as installation of high-efficiency equipment and control devices has not been promoted, whereas "Energy Conservation through Practice" such as appropriate management of temperature settings, and lighting switch On/Off have already been executed in many enterprises. As the main reason, about the half of SMEs answered "High Cost of Investment" and the next major reason was "It Does not Help Reduce Cost". From these reasons, it is found that SMEs have been promoted "Energy Conservation through Practice", however the effect of these non-investment activities are limited and most of SMEs in Japan should be skeptical for the return on investment (ROI) of the energy saving activities. In addition, energy related cost is not large especially in small enterprises and thus cost reduction benefit would be small and the benefit might not cover the installation and operation cost. Even if the benefit would cover the installation and operation cost, the investment recovery period would be long due to its large scale investment and small cost reduction. Because the installation of EMS does not reduce electricity cost itself but just supports to find rooms for optimal electricity utilization, some additional benefit should be essential to promote consumer side EMS.

\section{Approach to Solve Existing Challenges}

Assuming that consumer side EMS should contribute to effective electricity consumption, the installation benefit should be clarified, and moreover, it should be necessary to show if business enterprises would not install EMS, some problems or risks in business administration should be appeared. Therefore, an important purpose of this research should provide beneficial tools to evaluate EMS installation benefit, especially for business electricity consumers who manage offices, shops and buildings etc., by the clarification of EMS installation cost and cost reduction effects for some characteristic business types. Followings are basic concepts and approaches.

\section{1) Optimized energy consumption}

Optimized energy consumption should be defined as the energy consumption which maximizes profitability and amount of saving energy. This means that enterprises should be achieved saving energy without decreased productivity.

\section{2) Productivity changing by temperature}

Productivity changing by temperature should be one of good models to evaluate relation of energy saving and work performance. For example, an enterprise whose main business depends on the work performance of employees is necessary to consider different property of each employee if profitability of the enterprise would be estimated. With regard to retail business such as restaurant, supermarket etc., indoor temperatures might impact to their sales.

\section{3) Unknown variables}

Work performance for work room temperature or sales amount for shop temperature would be defined as stochastic variables. By the execution of Monte Carlo method using these stochastic variables, relation between energy management and enterprise profitability should be clarified and EMS installation benefit should be more accurate.

\section{4) Optimal setting}

Optimal settings for parameters such as temperature and distribution models used for Monte Carlo method are also needed to be considered through this approach. Historic data collection should be useful for accurate results.

\section{ESTABLISHMENT OF A BENEFIT QUANTIFICATION METHOD BY EMS FOCUSING ON PROFITABILITY}

In this section, profitability of consumer side EMS will be formulated along the concept considered in the last section.

\section{A. General EMS Installation Benefit Calculation}

Installation effect of EMS can be calculated as energy cost reduction provided by the EMS minus initial and accumulated operation cost of the EMS. Let initial cost be $C_{I}$, monthly operation cost be $C_{m}$, average monthly electricity reduction cost be $\Delta P_{m a}$, and payout period be $T$ (month), then the following equation should be satisfied.

$$
C_{I}+C_{m} \times T=\Delta P_{m a} \times T
$$


Fig. 4 represents the cost function of EMS installation and operation. If the break-even point would exist and sales revenue would not decrease, business administrators should make a decision to install EMS. Therefore, if EMS would not be used widely, it means that business administrators would not convince the break-even point existence in the near future and feel high risk for the initial investment recovery.

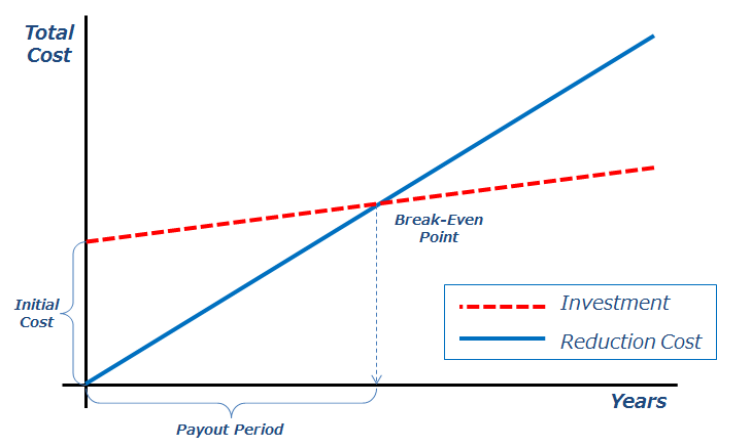

Fig. 4. Cost function of EMS installation and operation.

\section{B. Guarantee of Energy Cost Reduction and Maintaining Profitability}

In the installation of EMS, both the break-even point existence and the business profitability maintaining or improvement should be crucial. Therefore, the aspect of business profitability is considered in addition to the simple cost function showed in (1) in this paper. Let the average difference of monthly sales revenue except for the energy cost difference be $\Delta R_{m a}$, then the (1) would be changed as follows.

$$
C_{I}+C_{m} \times T=\left(\Delta P_{m a}+\Delta R_{m a}\right) \times T
$$

Because it is necessary to achieve both energy cost reduction and business profitability maintaining or improvement, the fluctuation of business profitability would be considered by changing settings of energy consumption equipment in this paper. For example, total profitability in case that temperature setting would be turn up $1{ }^{\circ} \mathrm{C}$ in summer season would be discussed. In the case, electricity cost would be down but it is necessary to consider performance or productivity changes.

\section{Formulation of Earning Structure}

The profit of a month can be calculated as the accumulated profit in business days in the month. Here, profitability change would be considered with 1 unit reduction of electricity consumption. It means measures such as $1{ }^{\circ} \mathrm{C}$ air-conditioner temperature turn up or $10 \%$ light turn off etc. As the first example, let the change of work performance be $L$, which is defined as the rate of variability for the average production amount $P_{A V E}$, then total production amount $P_{A L L}$ would be as follows.

$$
P_{A L L}=P_{A V E} \times(1+L)
$$

Let work performance variability of employee $i$ in temperature $t^{\circ} \mathrm{C}$ environment be $L_{i}(t)$, then total production amount $P_{A L L}$ in temperature $t{ }^{\circ} \mathrm{C}$ environment would be as follows.

$$
P_{A L L}=P_{A V E} \sum_{i=1}^{n}\left(1+L_{i}(t)\right)
$$

where $n$ is the number of employees in the enterprise.

Secondly, in retail and catering businesses which customers come into their business facilities such as shopping stores, restaurants etc., their indoor temperature might influence consumers' purchase behaviors. Then the rate of variability for purchased amount of customer $j$ in indoor temperature $t{ }^{\circ} \mathrm{C}$ environment be $B_{j}(t)$, the average sales revenue be $R_{A V E}$, then total sales revenue $R_{A L L}$ in the shop temperature $t^{\circ} \mathrm{C}$ environment would be as follows.

$$
R_{A L L}=R_{A V E} \sum_{j=1}^{m}\left(1+B_{j}(t)\right)
$$

where $m$ is the number of customers in the facility.

In above these two examples, optimal temperature for employee $i$ or customer $j$ can be defined as random variable. Therefore, these kinds of variables are treated as stochastic variables and profitability by EMS installation would be analyzed by the Monte Carlo method in this paper.

\section{Simulation AND Result Evaluation}

In this section various simulations and their results are described and results are evaluated for some model cases based on the concept described in the previous section.

\section{A. Definition of Model Case}

The first model in the previous section is used for the simulation. A certain business which outputs would be almost the same in same conditions should be selected, and the productivity difference would be considered by changing air-conditioner settings. The simulation will be executed with some different setting parameters, and then monthly and annual revenue of the business would be calculated. In this paper, productivity change would be calculated from June to September for the consideration of cooling demand and from December to March for the consideration of the heating demand based on the normal seasonal requirements in Japan.

\section{B. Formulation for Productivity Change Simulation}

The formulation of benefit quantification of EMS for the simulation model case is considered. Let average monthly

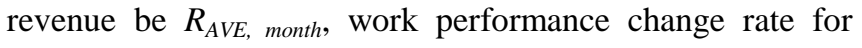
employee $i$ in temperature $t$ be $L_{i}(t)$, then revenue from June to September $R_{6-9}$ would be as follows.

$$
R_{6-9}=\sum_{\text {month }} R_{A V E, \text { month }} \sum_{i=1}^{n}\left(1+L_{i}(t)\right)
$$

where $n$ is the number of employees, month: June, July, August, September.

Same as the revenue from June to September, revenue from December to March $R_{12-3}$ would be as follows.

$$
R_{12-3}=\sum_{\text {month }} R_{A V E, \text { month }} \sum_{i=1}^{n}\left(1+L_{i}(t)\right)
$$

where month: December, January, February, March.

With regard to April, May, October and November, it is assumed that fluctuation of electricity cost would be small and energy cost in each month would be the same as average monthly electricity price. As the result, the annual revenue 
$R_{\text {year }}$ would be as follows.

$$
R_{\text {year }}=R_{6-9}+R_{12-3}+\sum_{\text {month }} R_{A V E, \text { month }}
$$

where month: April, May, October and November.

On the other hand, let average monthly energy cost be $C_{A V E \text {,month }}$, energy reduction rate for each month be $e_{\text {month }}$, then annual energy cost reduction $C_{\text {reduction,year }}$ would be as follows.

$$
C_{\text {reductionyear }}=\sum_{\text {month }=1}^{12} C_{A V E, \text { month }} \cdot e_{\text {month }}
$$

Therefore, annual revenue $R_{A L L}$ in this case would be as follows.

$$
R_{A L L}=R_{\text {year }}+C_{\text {reductionyear }}
$$

In order to clarify EMS installation effect, it is necessary to consider EMS installation and operation cost and payout period in (2), where $\Delta R_{m a}$ in (2) is the difference between $R_{A L L}$ and the revenue in the previous year.

\section{Setting Parameters and Simulation Scenarios}

Here, parameter values are defined for simulations.

\section{1) Setting parameters}

Assuming a general SME in consumer area, some parameters are defined and showed in Table I. Energy reduction rate per $1^{\circ} \mathrm{C}$ is defined referring to "Energy Conservation for Office Buildings" [9] provided by the Energy Conservation Center in Japan. Energy cost would be reduced with higher temperature settings of air-conditioner in summer season and with lower temperature settings in winter season.

TABLE I: SETTING PARAMETERS FOR SIMULATIONS

\begin{tabular}{cccc}
\hline \hline \multirow{2}{*}{$\begin{array}{c}\text { The number of } \\
\text { employees }\end{array}$} & $\begin{array}{c}\text { Average annual } \\
\text { revenue (USD) }\end{array}$ & $\begin{array}{c}\text { Electricity Cost Reduction rate } \\
\text { per }+1{ }^{\circ} \mathrm{C}\end{array}$ \\
\cline { 3 - 4 } & $1,000,000$ & Summer & Winter \\
\hline 50 & $10 \%$ & $-10 \%$ \\
\hline \hline
\end{tabular}

\section{2) Stochastic variables and base populations}

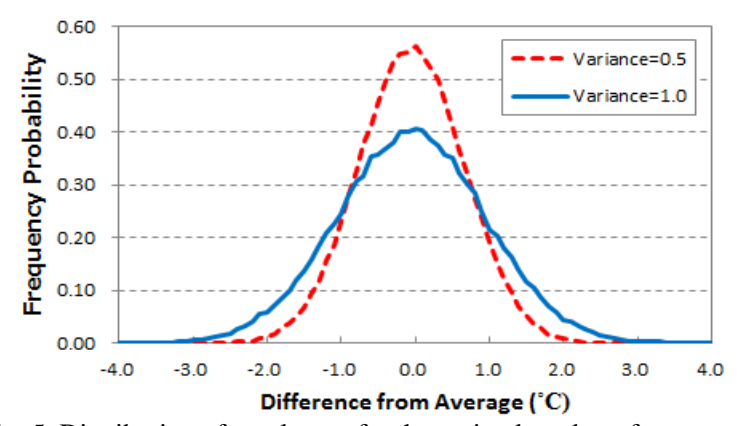

Fig. 5. Distribution of employees for the optimal work performance temperature difference from average.

Work environment temperature which maximizes employee's work performance is defined as a stochastic variable. 50 employees are retrieved from the base population in which each employee has individual preferred work environment temperature which maximizes employee's work performance and the number of preferred temperatures conforms to normal distribution. Fig. 5 shows normal distribution curves for variance 1.0 and 0.5 , and most members are included in the scope of $\pm 3^{\circ} \mathrm{C}$ area with variance: 1.0 , and $\pm 2^{\circ} \mathrm{C}$ area with variance: 0.5 . In this paper variance is set at 1.0 as the base variance. In the simulation, 50 employees are selected randomly and the production amount in a certain work temperature environment will be calculated considering performance change for all 50 employees by the work temperature environment. In order to reduce the variability of the simulation, 10,000 times of simulation for each simulation

\begin{tabular}{|c|c|c|}
\hline Stochastic & Variables & $\begin{array}{c}\text { Work environment temperature } \\
\text { which maximizes employee's } \\
\text { work performance }\end{array}$ \\
\hline \multirow{3}{*}{$\begin{array}{l}\text { Distribution of } \\
\text { employees for the } \\
\text { optimal work } \\
\text { performance } \\
\text { temperature: } \\
\text { Average }\end{array}$} & Type & Normal Distribution \\
\hline & $\begin{array}{l}\text { Average } \\
\left(t_{A V E_{-} S: \text { Summer }},\right. \\
\left.t_{A V E_{-} W: \text { Winter }}\right)\end{array}$ & $\begin{array}{l}26{ }^{\circ} \mathrm{C} \text { (Summer) } 22{ }^{\circ} \mathrm{C} \text { (Winter), } \\
27{ }^{\circ} \mathrm{C} \text { (Summer) } 21{ }^{\circ} \mathrm{C} \text { (Winter), }\end{array}$ \\
\hline & Variance & $1.0,0.5$ \\
\hline
\end{tabular}
scenario are executed. Table II shows stochastic variables and base distributions.

\section{3) Simulation scenarios}

In this paper, simulations will be executed for several scenarios including 4 patterns of electricity cost for total sales revenue, 4 patterns of work performance reduction rate per 1 ${ }^{\circ} \mathrm{C}$ change, 2 combinations of average temperature which maximize employees' performance, 3 combinations of energy reduction settings and 2 combinations of setting improved temperature. Work performance reduction rates were defined referring to existing researches [4], [5] related to productivity and temperature. Table III shows setting parameters for

\begin{tabular}{|c|c|}
\hline Parameter & Values \\
\hline $\begin{array}{l}\text { Rate of Electricity Cost per } \\
\text { Revenue }\end{array}$ & $\begin{array}{l}0 \%, 1 \%, 5 \%, 10 \% \\
(0 \% \text { model is just used for comparison) }\end{array}$ \\
\hline $\begin{array}{l}\text { Work Performance Reduction } \\
\text { Rate per } 1^{\circ} \mathrm{C} \text { : }\end{array}$ & $0 \%, 1 \%, 2 \%, 3 \%$ \\
\hline $\begin{array}{l}\text { Temperature Settings in } \\
\text { Work Environment } \\
\left(\mathrm{t}_{\text {SET_S: Summer, }} \mathrm{t}_{\text {SET_w: Winter }}\right) \\
\end{array}$ & $\begin{array}{ll}26{ }^{\circ} \mathrm{C} \text { (Summer) } & 22{ }^{\circ} \mathrm{C} \text { (Winter), } \\
27{ }^{\circ} \mathrm{C} \text { (Summer) } & 21{ }^{\circ} \mathrm{C} \text { (Winter), } \\
28{ }^{\circ} \mathrm{C} \text { (Summer) } & \left.20{ }^{\circ} \mathrm{C} \text { (Winter }\right)\end{array}$ \\
\hline $\begin{array}{l}\text { Setting Improved Temp. for } \\
\text { Energy Saving } \\
\left(\mathrm{t}_{\text {IMP_S: Summer, }} \mathrm{t}_{\text {IMP_W: Winter })}\right.\end{array}$ & $\begin{array}{l}\left.+1{ }^{\circ} \mathrm{C}(\text { Summer }),-1{ }^{\circ} \mathrm{C} \text { (Winter }\right) \\
\left.+2{ }^{\circ} \mathrm{C}(\text { Summer }),-2{ }^{\circ} \mathrm{C} \text { (Winter }\right)\end{array}$ \\
\hline
\end{tabular}
simulation scenarios.

TABLE III: SIMULATION SCENARIOS SETTING PARAMETERS

\section{Simulation Results Evaluation}

Based on simulation scenarios, expected revenues are calculated and results are evaluated.

1) Revenue simulation case for general enterprise model in Japan:

As the first simulation, following settings are selected as the base model considering general situation in Japan.

- Average temperature which maximize employees performance: $26^{\circ} \mathrm{C}($ Summer $) ; 22^{\circ} \mathrm{C}$ (Winter)

- Changed Temperature Settings in Work Environment: $27^{\circ} \mathrm{C}$ (Summer); $21^{\circ} \mathrm{C}$ (Winter)

- Setting improved temperature for Energy Saving: +1 ${ }^{\circ} \mathrm{C}$ (Summer); $-1{ }^{\circ} \mathrm{C}$ (Winter), (Current settings: 26 ${ }^{\circ} \mathrm{C}$ (Summer); $22{ }^{\circ} \mathrm{C}$ (Winter))

Table IV shows simulation result for the base model. The 
rate of electricity cost for total revenue is $0 \%$ means no electricity cost, and therefore expected revenues show the minimum values compared with other same performance decrease rate scenarios. Here, by the reduction of electricity cost, how expected sales revenue would change should be discussed. The result shows most of expected revenues for companies which rate of electricity cost for total sales 1\% 5\% are smaller than the base revenues. Although it depends on the unit price of electricity, electricity consumption in the site would be small in Japan if rate of electricity cost was 1 5\% of total revenue. In such cases, it is found that additional benefit by the electricity cost reduction would be small, so cost reduction benefit would be canceled easily if productivity would decrease by the energy reduction. On the other hand, in an enterprise which energy cost is $10 \%$ of total revenue, expected revenue would be increased even if $1 \%$ of performance would be decreased.

\begin{tabular}{|c|c|c|c|c|}
\hline $\begin{array}{c}\text { Rate of } \\
\text { Electricity } \\
\text { Cost for } \\
\text { Total } \\
\text { Revenue } \\
(\%)\end{array}$ & $\begin{array}{l}\text { Performance } \\
\text { Decrease } \\
\text { Rate for } 1{ }^{\circ} \mathrm{C} \\
\quad(\%)\end{array}$ & $\begin{array}{c}\text { Maximum } \\
\text { Expected } \\
\text { Revenue } \\
\text { (USD) }\end{array}$ & $\begin{array}{c}\text { Minimum } \\
\text { Expected } \\
\text { Revenue } \\
\text { (USD) }\end{array}$ & $\begin{array}{c}\text { Average } \\
\text { Expected } \\
\text { Revenue } \\
\text { (USD) }\end{array}$ \\
\hline $0 \%$ & $0 \%$ & $1,000,000$ & $1,000,000$ & $1,000,000$ \\
\hline $0 \%$ & $1 \%$ & 996,148 & 990,836 & 993,337 \\
\hline $0 \%$ & $2 \%$ & 991,922 & 981,676 & 986,673 \\
\hline $0 \%$ & $3 \%$ & 987,244 & 971,346 & 980,014 \\
\hline $1 \%$ & $0 \%$ & $1,001,000$ & $1,001,000$ & $1,001,000$ \\
\hline $1 \%$ & $1 \%$ & 996,635 & 991,734 & 994,333 \\
\hline $1 \%$ & $2 \%$ & 992,579 & 982,117 & 987,667 \\
\hline $1 \%$ & $3 \%$ & 988,450 & 973,559 & 981,023 \\
\hline $5 \%$ & $0 \%$ & $1,005,000$ & $1,005,000$ & $1,005,000$ \\
\hline $5 \%$ & $1 \%$ & $1,000,804$ & 995,644 & 998,335 \\
\hline $5 \%$ & $2 \%$ & 996,745 & 986,963 & 991,651 \\
\hline $5 \%$ & $3 \%$ & 991,889 & 977,753 & 984,969 \\
\hline $10 \%$ & $0 \%$ & $1,010,000$ & $1,010,000$ & $1,010,000$ \\
\hline $10 \%$ & $1 \%$ & $1,005,871$ & $1,000,926$ & $1,003,334$ \\
\hline $10 \%$ & $2 \%$ & $1,002,569$ & 991,672 & 996,657 \\
\hline $10 \%$ & $3 \%$ & 997,532 & 982,453 & 989,996 \\
\hline
\end{tabular}

$\left(T_{A V E_{-} S}=26^{\circ} \mathrm{C}, T_{A V E_{-} W}=22^{\circ} \mathrm{C}\right.$ VARIANCE $\Sigma^{2}=1.0$

$\left.t_{S E T_{-} S}=27{ }^{\circ} \mathrm{C}, t_{S E T_{-} W}=21{ }^{\circ} \mathrm{C} \quad t_{I M P_{-} S}=+1{ }^{\circ} \mathrm{C}, t_{I M P_{-} W}=-1{ }^{\circ} \mathrm{C}\right)$

Gray colored cells mean calculated revenue is more than the base revenue.

\section{2) Revenue simulation case for excess energy consumption enterprise model}

It is expected that EMS benefit should be large for companies which energy saving activities have not been addressed so far. For this type of simulation, the model which air-conditioners have excess settings is used. Table V shows the simulation result for the model which has excess energy utilization settings. In this case, current work environment temperature settings are $25^{\circ} \mathrm{C}$ in summer season and $23^{\circ} \mathrm{C}$ in winter season and both are changed to $26{ }^{\circ} \mathrm{C}$ and $22{ }^{\circ} \mathrm{C}$ respectively. Because work environment temperature would be the average temperature which maximizes employees' performance, in most cases expected revenues would increase and EMS installation and operation cost should be able to be covered. Generally expected revenues would be reduced with performance decrease rate, however the result shows revenues with high performance decrease rate have large values in this case. This is because the current setting generates bad impact largely compared with low work performance decrease rate and these bad impacts would be improved by the new optimal setting.

TABLE V: SIMULATION RESULTS

\begin{tabular}{|c|c|c|c|c|}
\hline $\begin{array}{c}\text { Rate of } \\
\text { Electricity } \\
\text { Cost for } \\
\text { Total } \\
\text { Revenue }(\%) \\
\end{array}$ & $\begin{array}{l}\text { Performance } \\
\text { Decrease } \\
\text { Rate for } 1{ }^{\circ} \mathrm{C} \\
\quad(\%)\end{array}$ & $\begin{array}{l}\text { Maximum } \\
\text { Expected } \\
\text { Revenue } \\
\text { (USD) }\end{array}$ & $\begin{array}{c}\text { Minimum } \\
\text { Expected } \\
\text { Revenue } \\
\text { (USD) }\end{array}$ & $\begin{array}{l}\text { Average } \\
\text { Expected } \\
\text { Revenue } \\
\text { (USD) }\end{array}$ \\
\hline $0 \%$ & $0 \%$ & $1,000,000$ & $1,000,000$ & $1,000,000$ \\
\hline $0 \%$ & $1 \%$ & $1,002,489$ & 997,553 & $1,000,011$ \\
\hline $0 \%$ & $2 \%$ & $1,005,053$ & 994,875 & 999,969 \\
\hline $0 \%$ & $3 \%$ & $1,007,980$ & 992,660 & $\overline{999,992}$ \\
\hline $1 \%$ & $0 \%$ & $1,001,000$ & $1,001,000$ & $1,001,000$ \\
\hline $1 \%$ & $1 \%$ & $1,003,261$ & 998,691 & $1,001,004$ \\
\hline $1 \%$ & $2 \%$ & $1,006,269$ & 996,213 & $1,001,014$ \\
\hline $1 \%$ & $3 \%$ & $1,008,565$ & 993,309 & $1,001,024$ \\
\hline $5 \%$ & $0 \%$ & $1,005,000$ & $1,005,000$ & $1,005,000$ \\
\hline $5 \%$ & $1 \%$ & $1,007,581$ & $1,002,713$ & $1,005,008$ \\
\hline $5 \%$ & $2 \%$ & $1,010,245$ & 999,952 & $1,005,003$ \\
\hline $5 \%$ & $3 \%$ & $1,013,359$ & 997,343 & $1,005,020$ \\
\hline $10 \%$ & $0 \%$ & $1,010,000$ & $1,010,000$ & $1,010,000$ \\
\hline $10 \%$ & $1 \%$ & $1,012,384$ & $1,007,483$ & $1,010,007$ \\
\hline $10 \%$ & $2 \%$ & $1,016,651$ & $1,005,153$ & $1,010,013$ \\
\hline $10 \%$ & $3 \%$ & $1,017,143$ & $1,002,022$ & $1,010,009$ \\
\hline
\end{tabular}

\section{3) Revenue simulation case for excess energy saving enterprise model}

For this type of simulation, the model which air-conditioners have excess settings for energy saving is used. Table VI shows the simulation result for the model which has excess energy saving settings. In this case, current work environment temperature settings are $27^{\circ} \mathrm{C}$ in summer seasons and $21^{\circ} \mathrm{C}$ in winter seasons and both are changed to $28^{\circ} \mathrm{C}$ and $20^{\circ} \mathrm{C}$ respectively, although optimal work environment temperatures are $26^{\circ} \mathrm{C}$ and $22^{\circ} \mathrm{C}$ respectively.

\begin{tabular}{|c|c|c|c|c|}
\hline $\begin{array}{c}\text { Rate of } \\
\text { Electricity } \\
\text { Cost for } \\
\text { Total } \\
\text { Revenue } \\
(\%)\end{array}$ & $\begin{array}{l}\text { Performance } \\
\text { Decrease } \\
\text { Rate for } 1{ }^{\circ} \mathrm{C} \\
(\%)\end{array}$ & $\begin{array}{l}\text { Maximum } \\
\text { Expected } \\
\text { Revenue } \\
\text { (USD) }\end{array}$ & $\begin{array}{l}\text { Minimum } \\
\text { Expected } \\
\text { Revenue } \\
\text { (USD) }\end{array}$ & $\begin{array}{l}\text { Average } \\
\text { Expected } \\
\text { Revenue } \\
\text { (USD) }\end{array}$ \\
\hline $0 \%$ & $0 \%$ & $1,000,000$ & $1,000,000$ & $1,000,000$ \\
\hline $0 \%$ & $1 \%$ & 989,097 & 984,058 & 986,664 \\
\hline $0 \%$ & $2 \%$ & 978,757 & 968,476 & 973,331 \\
\hline $0 \%$ & $3 \%$ & 967,240 & 951,800 & 959,954 \\
\hline $1 \%$ & $0 \%$ & $1,002,000$ & $1,002,000$ & $1,002,000$ \\
\hline $1 \%$ & $1 \%$ & 991,136 & 985,820 & 988,665 \\
\hline $1 \%$ & $2 \%$ & 980,534 & 969,940 & 975,302 \\
\hline $1 \%$ & $3 \%$ & 969,581 & 953,401 & 961,967 \\
\hline $5 \%$ & $0 \%$ & $1,010,000$ & $1,010,000$ & $1,010,000$ \\
\hline $5 \%$ & $1 \%$ & 999,076 & 994,396 & 996,667 \\
\hline $5 \%$ & $2 \%$ & 988,077 & 978,177 & 983,365 \\
\hline $5 \%$ & $3 \%$ & 977,431 & 962,659 & 969,972 \\
\hline $10 \%$ & $0 \%$ & $1,020,000$ & $1,020,000$ & $1,020,000$ \\
\hline $10 \%$ & $1 \%$ & $1,009,023$ & $1,004,108$ & $1,006,672$ \\
\hline $10 \%$ & $2 \%$ & 998,999 & 988,746 & 993,352 \\
\hline $10 \%$ & $3 \%$ & 987,711 & 971,920 & 979,964 \\
\hline
\end{tabular}

The result shows that expected revenues would decrease except for the scenario which has the rate of electricity cost for total revenue is $10 \%$ and performance decrease rate for $1{ }^{\circ} \mathrm{C}$ is $1 \%$. This means excess energy saving has high 
possibility of companies' profitability reduction. Although it is important to reduce environmental load for companies' business administration, the balanced energy utilization considering both environmental and business sustainability is essential.

\section{E. Holistic Evaluation of the Simulation Approach}

In above these simulations, EMS installation and operation costs are not considered. Except for the second model, the benefit should not be enough for covering EMS related cost even in the most effective case, and therefore it is difficult to get additional benefit for most companies if business productivity would decrease. $1 \%$ of performance reduction is the same as 0.08 hour ( 4.8 minutes) work time reduction for 8 hours work per day companies, and it means about 5 minutes additional no work time occurrence by the energy reduction lead to bad impact to total profitability for most companies. Whereas detailed researches for the relation between work environment and performance, and energy saving without impact for enterprises' business productivity should be necessary, EMS should be used for a waste energy reduction and optimal settings decision measures.

From the simulation result for the second model, which is excess energy consumption enterprise model, EMS has high possibility to provide various benefits for companies which have conducted insufficient energy saving activities. Because current electricity utilization amount would be larger than optimal amount in these companies, benefits from energy saving must be generated. Therefore, it should be very important to find optimal settings considering employees and machines performance in consumer side energy management.

In this time, the impact of the employees' performance change on an enterprise's revenue was discussed and evaluated using a simulation approach. Also, similar approach can be used for the impact quantification of the consumers' purchase behavior change described as the second sample model in V. In addition, the proposed approach can be used for the decision of work environment parameters such as optimal temperature settings. By the continuous collection of temperature and performance data, optimal work environment settings can be decided more effectively and accurately.

\section{CONCLUSIONS}

In order to clarify the real effect of consumer side EMS, this paper proposed an approach to evaluate the impact of energy reduction on the enterprise productivity, which has not been considered enough, whereas many researches for energy reduction effect by EMS have been studied. As the result of simulations, it was clarified that EMS should be used for waste energy reduction mainly and energy management activities should not impact on enterprise productivity and profitability. In addition it is important for electricity consumers to understand that excess energy saving results in revenue or productivity reduction. Generally the impact on energy cost by energy reduction is much smaller than that of profit of the enterprise, so balanced energy utilization considering both environmental and business sustainability issues is essential. Also, the paper showed that it was important to find optimal environment, and EMS and the proposed method can be contribute to decide optimal settings for energy supply equipment. As the future work, renewable energy sources (RES) should be added to this evaluation approach. Although optimal energy consumption from the aspect of enterprises' productivity might require larger energy compared with optimal energy amount from the aspect of $\mathrm{CO} 2$ emission, RES, which is environmental friendly but expensive, can be a solution for such the trade-off problem.

\section{REFERENCES}

[1] Energy Conservation Policies of Japan, Agency of Natural Resources and Energy Conservation and Renewable Energy Department, 2011.

[2] H. C. Tung, K. F. Tsang, L. L. Lai, K. L. Lam, and H. Y. Tung, "Hybrid energy management solution for smart building," in Proc. IEEE Int. Conference on Consumer Electronics, Jan. 2011, pp. 509-510.

[3] H. Xuan et al., "Efficient multiple gateway system for WSN management in BEMS," in Proc. 9th Int. Con. on Networked Sensing Systems, 2012, pp. 1-2.

[4] Z. Peng et al., "An energy management system for building structures using a multi-agent decision-making control methodology," IEEE Trans. on Industry Applications, vol. 49, no. 1, pp. 322-330, 2013.

[5] K. Park, Y. Kim, S. Kim, K. Kim, W. Lee and H. Park, "Building Energy Management System based on Smart Grid," in Proc. 33rd International Telecommunications Energy Conference, 2011, pp. 1-4

[6] O. Seppanen, W. J. Fisk, and D. Faulkner, "Cost benefit analysis of the night-time ventilative cooling in office building," Lawrence Berkeley National Laboratory, Jun. 2003.

[7] S. Tanabe, M. Haned, and N. Nishipana, "Indoor environmental quality and productivity," REHVA Journal, pp. 26-31, Jun. 2007.

[8] 2010 White Paper on Small and Medium Enterprises in Japan, Ministry of Economy, Trade and Industry and Japan Small Business Research Institute, Sep. 2010.

[9] Energy Conservation for Office Buildings, the Energy Conservation Center, Japan, 2010

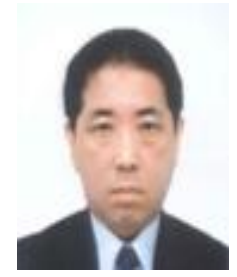

Ken Kuroda is a doctoral student in electrical power engineering at the Graduate School of Environment and Energy Engineering, Waseda University. He also works for Fujitsu Limited as a systems engineer and a consultant since 1993. He received the B.S. and MBA degrees from Waseda University. His research interests are demand side optimal power supply and demand, and their related information systems.

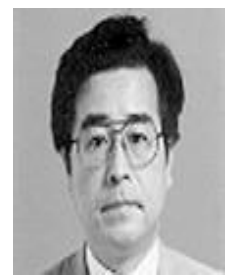

Hideki Magori received the B.S. degree in mathematics from Kyoto University, Japan, and the $\mathrm{Ph} . \mathrm{D}$. degree in electrical engineering from Tokyo Metropolitan University. He is especially interested in the application of combinatorial optimization methods to the planning and scheduling problems.

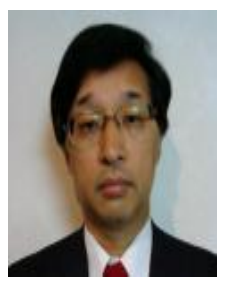

Tomiyasu Ichimura received the M.S. degree in mathematics from Rikkyo University, Japan and the $\mathrm{Ph} . \mathrm{D}$. degree in engineering from Waseda University, Japan. He works for Fujitsu Limited as a system engineer since 1986 and is interested in asset management including optimization methods for maintenance and replacement of power asset.

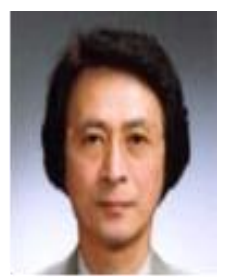

Ryuichi Yokoyama received the Ph.D. degree in electrical engineering from Waseda University, Japan. $\mathrm{He}$ is currently a professor at the Graduate School of Environment and Energy Engineering, Waseda University. His fields of interest include control and optimization of large-sale systems and applications of artificial intelligence to power systems. 